\title{
A novel analytical model for determining erosion from hole erosion tests
}

\author{
Weiling $\mathrm{Cai}^{1}$, Manash Bora ${ }^{2}$, Sreeja Pekkat ${ }^{3}$, Sanandam Bordoloi ${ }^{4}$, Ankit Garg ${ }^{1}$, and \\ Sreedeep $\mathrm{S}^{5}$ \\ ${ }^{1}$ Shantou University \\ ${ }^{2}$ Indian Institute of Technology Guwahati \\ ${ }^{3}$ IIT Guwahati Department of Civil Engineering \\ ${ }^{4} \mathrm{HKUST}$ \\ ${ }^{5}$ IIT Guwahati
}

July 25, 2020

\begin{abstract}
Determination of erosion characteristics is of great significance to assess the stability of geotechnical infrastructures that are subjected to seepage. Hole erosion tests (HETs) are the popular and simple laboratory measurements that have been used to determine erosion characteristics. These tests are indicative of the quantity of soil loss in term of internal erosion that can occur during seepage. It is noted that there are not many studies that focus on the development of theoretical model describing the erosion process (i.e. sediment detachment and transport) in HETs. The aim of this study is to propose a theoretical model based on Bernoulli's principle to interpret the erosion measurements from HETs and employ the results for estimating erosion characteristics of soils. An analytical equation was deduced from a physically based model incorporating Bernoulli's principle and erosion constitutive law for internal erosion within a soil pipe driven by pressure gradient. The analytical equation could be applied to determine the temporal development of eroded soil loss, radial erosion propagation, erosion rate, hydraulic shear stress, and pressure drop. The utility of proposed analytical solution was validated using a series of HETs performed in this study. Based on the novel analytical solution, erosion characteristics could be derived from the known realistic propagation of radial erosion.
\end{abstract}

\section{Introduction}

Internal erosion progressively erodes geotechnical infrastructures, such as earthen dam, road embankment, and landfill cover through preferential flow or rise in water level (Nieber et al. 2019). Internal erosion driven by seepage force would lead to the change of soil properties (i.e., soil stiffness, porosity, permeability), and further trigger the occurrence of piping, settlement, sinkhole, landslide, and even collapse (Cividini and Gioda 2004; Elkholy et al. 2015; Sato and Kuwano 2018; Indiketiya et al. 2019). The damage of geotechnical infrastructures induced by internal erosion is a worldwide issue and has caused substantial socioeconomic loss (Foster et al. 2000; Zhang et al. 2020). Therefore, it is essential to study the influence of internal erosion process on the susceptibility, vulnerability, instability, and even failure of hydraulic earth structures (Foster et al. 2000; Cividini et al. 2009). The interpretation of erosion process is significant for the safety surveillance of the earthen structures to reveal failure mechanism and provide advance warning of internal erosion (Foster et al. 2002; Fell et al. 2003; Chang and Zhang 2013; Haghighi et al. 2013).

Erosion characteristics including erosion coefficient and critical shear stress are generally based on mechanical responses of the soils to water flow (Wall and Fell 2004a). Erosion characteristics have been extensively studied as the governing factors in the process of internal erosion (Arulanandan and Perry 1983). The Hole 
Erosion Test (HET) is an effective and widely adopted approach to study the mechanical responses of the soils under given hydraulic gradient (Wan and Fell 2004b; ASTM 2006; Fattahi et al. 2017). The HET approach was originated from the critical hydraulic gradient method, which was commonly applied to evaluate the safety of earthen dams in the field (Nadal-Romero et al. 2011; Chang and Zhang 2013; Haghighi et al. 2013). Existing studies about HETs found that erosion characteristics were mainly influenced by soil basic properties such as Atterberg limits, clay percentage, soil density, water content, and grain size distribution (Arulanandan and Perry 1983; Wall and Fell 2004b; Indraratna et al. 2008; Benahmed and Bonelli 2012; Haghighi et al. 2013; Pereyra et al. 2019). HETs have been also utilized to qualitatively understand the potential of dam failures (Fell et al. 2003; Wan and Fell 2004a).

Generally, the mechanism of internal erosion is idealized as a soil pipe model (Nieber et al. 2019). The moving fluid flow acts on the soil boundaries causing the deformation (i.e. erosion) of the soil pipe while the enlargement of the soil pipe in turn affects the flow motion (Onate et al. 2011). This highly coupled mechanism of internal erosion induced by hydraulic shear stress is recognized as a fluid-structure interaction problem (Onate et al. 2011). Several studies have been carried out to explore the process of internal erosion in a soil pipe experimentally and theoretically. Chang et al. (2011), Fattahi et al. (2017), and Zhang et al. (2020) conducted experimental investigations on the internal erosion and suggested empirical equations of nonlinear incremental radial erosion propagation. Dumberry et al. (2017) and Xie et al. (2018) applied X-ray microcomputed tomography and invented a visual HET apparatus to observe the temporal variation of internal erosion. Besides, theoretical formulations were successively developed to model the erosion process governed by Bernoulli principles. Wan and Fell (2004a) proposed the erosion constitutive law expressing the linear relationship between erosion rate and hydraulic shear stress to capture the process of sediment detachment in a soil pipe (Haghighi et al. 2013). Bonelli and Brivois (2008) found that the radial erosion propagation under the given pressure drop obeyed a scale exponential law. Sang et al. (2015) developed semi-physically models for predicting the enlargement of the hole in the HET. The mechanism of progressive internal erosion leading to instability of the structure was interpreted and modelled by Onate et al. (2011) and Hicher (2013). Benaissa et al. (2012) and Říha and Jandora (2015) investigated the spatial distribution of hydraulic pressure conditions in the soil pipe. Nguyen and Indraratna (2020) developed the energy transformation model describing the fluid-solid interaction in the dynamic erosion process. Many studies (Cividini and Gioda 2004, Bonelli et al. 2006, Benaissa et al. 2012, Hicher 2013, Parron Vera et al. 2014, Yang et al. 2020, and Zhang et al. 2020) performed the numerical simulation based on the mass conservation equations for predicting sediment transport. However, these numerical approaches using the computational fluid dynamics or finite element method had limitation in determining erosion characteristics of soils in the HET (Lachouette et al. 2008). Limited studies considered erosion characteristics (especially erosion coefficient) in the theoretical deductions of numerical simulation, in which soil erosion were mostly considered as soil dispersity or diffusion instead of shearing movement of soil particles (Onate et al. 2011; Hicher 2013; Nieber et al. 2019). Bernatek-Jakiel and Poesen (2018) and Wilson et al. (2018) pointed out that the mechanistic mathematical formulations explaining sediment detachment and transport within soil pipes have not been fully established yet.

The main objective of this study is to formulate a theoretical model for interpretation of the erosion process (sediment detachment as well as transport) in the HETs. Bernoulli's equation and erosion constitutive law has been adopted for formulation of the model. The constitutive relationship between erosion rate and hydraulic shear stress was developed into a second-order nonlinear ordinary differential function. An analytical solution was deduced to determine the realistic erosion propagation with an assumption of homogeneous radial erosion along the length of the hole. The analytical solution was substituted into the model to deduce the expression of temporal variations of pressure conditions. Furthermore, a new equation generated from the model was proposed to determine erosion coefficient from the realistic variation of the measured sediment in the soil pipe. Finally, the validity of the proposed model has been examined by performing the HETs with pre-formed soil pipes on a sandy lean clay subjected to different hydraulic conditions. The advantage of the proposed model is that the formulation accounts for the change in radius of the hole during erosion with given erosion coefficient. 


\section{Development of Mathematical Model for Internal erosion}

\subsection{Establishment of constitutive relationships}

In the erosion process, the fluid exerts hydraulic shear stress $(\tau)$ on the soil pipe wall at the solid-fluid interface, causing continuous soil loss at the rate of $\dot{\varepsilon}$ (erosion rate). Previous studies (Arulanandan and Perry1983; Briaud et al. 2001; Wan and Fell 2004a; Bonelli and Brivois 2008) have confirmed the erosion constitutive law as given by

$$
\dot{\varepsilon}=K\left(\tau-\tau_{c}\right)
$$

where $K=$ erosion coefficient, and $\tau_{c}=$ critical shear stress. The erosion coefficient, also known as the coefficient of erodibility, is usually taken as a constant parameter describing the soil properties (Wan and Fell 2004a; Haghighi et al. 2013). Wan and Fell (2004a) proposed laboratory testing method to determine the erosion coefficient in the pre-formed soil pipe. The erosion law is generally employed to explain stressstrain relationship on the soil pipe periphery (Nieber et al. 2019). The erosion coefficient reflects the binding force of the inner soil layer to resist wall shear stress. A higher magnitude of erosion coefficient indicates a weak cohesion in the soil, that is easy to be detached. Critical shear stress is considered as the surficial shear strength influenced by roughness features. When hydraulic shear stress (i.e., external stress) exceeds the critical shear stress applied on the soil-water contact surface, the soil body is sheared with a linear deformable response in the form of particle detachment (Parron Vera et al. 2014). As shown in Fig. 1 (a), the path of the fluid is extended due to the presence of hydraulic shear stress. The viscosity of the fluid and the roughness of soil surface result in the velocity gradient, which generates shear action (Benaissa et al. 2012).

The movement of soil particles (i.e., erosion) is regarded as the corresponding shear strain. The erosion rate $\left(\dot{\varepsilon}, \mathrm{kg} / \mathrm{m}^{2} / \mathrm{s}\right)$ is defined as the mass loss $(m, \mathrm{~kg})$ of soil per area $\left(A, \mathrm{~m}^{2}\right)$ and time $(t, \mathrm{~s})$.

$$
\dot{\varepsilon}=\frac{m}{A \bullet t}
$$

The fluid erodes the soil layer with a certain rate, defined as eroded $\operatorname{depth}\left(d_{\varepsilon}, \mathrm{m} / \mathrm{s}\right)$. Based on the eroded soil volume, the eroded depth can be determined by

$$
d_{\varepsilon}=\frac{m}{\rho_{s} \bullet A \bullet t}
$$

The eroded depth and erosion rate can both be utilized to estimate the rate of soil loss. Shear strain $(\gamma$, dimensionless) induced by hydraulic shear stress in soil body, therefore, can be expressed as

$$
\gamma=\frac{V}{d_{\varepsilon}}
$$

where $\mathrm{V}$ is the velocity of the fluid.

\subsection{Determination of hydraulic shear stress}

The fluid in the soil pipe generally follows the Bernoulli's equation. An idealized pipe model has been used to simulate the erosion process in the HET. The cylindrical path with a length of $L$ and a radius of $R$ is regarded as control volume, as indicated in Fig. 1 (b). The fluid travels through soil body following the force-equilibrium equation and Bernoulli's Energy equation, which are given by

$$
P_{1} A-P_{2} A-\tau \bullet 2 \pi R L=0
$$




$$
\left(Z_{1}+\frac{P_{1}}{\rho_{w} g}+\frac{V^{2}}{2 g}\right)_{\text {in }}-h_{f}=\left(Z_{2}+\frac{P_{2}}{\rho_{w} g}+\frac{V^{2}}{2 g}\right)_{\text {out }}
$$

As designed in the HET, the eroded path in the experiential setup is horizontal (i.e., $Z=0$ ). Therefore, the diameters of inlet and outlet are expected to be the same with uniform erosion (i.e., the velocities are constant). From equation [5], shear stress can be obtained by

$$
\tau=\frac{\left(P_{1}-P_{2}\right) \bullet R}{2 L}
$$

Friction loss $\left(h_{f}\right)$ is determined by

$$
h_{f}=\frac{P_{1}-P_{2}}{\rho_{w} g}
$$

Combining equation [7] and equation [8],

$$
h_{f}=\frac{2 L \tau}{R \rho_{w} g}
$$

Friction loss in the eroded path is calculated by Darcy-Weishach equation (Nieber et al. 2019),

$$
h_{f}=\frac{32 \nu \bullet L V}{D^{2} g}
$$

Where $\nu$ is kinematic viscosity, and $D$ is the diameter of the eroded path.

Substitute equation [10] into equation [9], shear stress can be further expressed as

$$
\begin{aligned}
& \frac{32 \nu \bullet L V}{D^{2} g}=\frac{2 L \tau}{R \rho_{w} g} \\
& \tau=\frac{4 \nu Q \rho_{w}}{\pi R^{3}}
\end{aligned}
$$

\subsection{Prediction of eroded path and erosion coefficient}

Equation [12] suggests that hydraulic shear stress is the function of fluid properties and the radius. In the specific test or condition, the given fluid is assumed to be unaltered (i.e., $\nu, \rho$, and $\mathrm{Q}$ are viewed as constants), even though carrying more soil particles will change fluid density and viscosity slightly. Therefore, shear stress can be also expressed as

$$
\tau=a \frac{1}{R^{3}}
$$

Where $a=\frac{4 \nu Q \rho_{w}}{\pi}$. The radius of the eroded path is considered as the function of time (i.e., $R=R(t)$ ).

Erosion rate can be defined by

$$
=\frac{\mathrm{dm}}{\mathrm{Adt}}=\frac{\rho_{s} \mathrm{dV}}{\mathrm{Adt}}=\frac{\rho_{s} \bullet 2 \pi R \bullet L \bullet d R}{2 \pi R L \bullet d t}=\frac{\rho_{s} \mathrm{dR}}{\mathrm{dt}}
$$


Based on equation [1], erosion coefficient is calculated by the differential equation,

$$
K=\frac{d \dot{\varepsilon}}{\delta \tau}
$$

It becomes as,

$$
\frac{d \dot{\varepsilon}}{\mathrm{dt}}=K \frac{\mathrm{d}}{\mathrm{dt}}
$$

Replace equation [13] and [14] into equation [16]

$$
\frac{\rho_{s} \bullet d\left(\frac{\mathrm{dR}}{\mathrm{dt}}\right)}{\mathrm{dt}}=K a \frac{d\left(\frac{1}{R^{3}}\right)}{\mathrm{dt}}
$$

Equation [17] is transformed into

$$
\rho_{s} \bullet R^{\prime \prime}=K a \frac{-3}{R^{4}} R^{\prime}
$$

Organize,

$$
R^{\prime \prime}+\frac{3 K a}{\rho_{s}} \bullet \frac{1}{R^{4}} R^{\prime}=0
$$

Solving the equation [19],

$$
R=\left(\frac{4 K a}{\rho_{s}} t+C\right)^{\frac{1}{4}}
$$

Equation [20] is further simplified as,

$$
R=\lambda(t+C)^{\frac{1}{4}}
$$

Thus,

$$
\begin{aligned}
& R^{\prime}=\frac{\lambda}{4}(t+C)^{-\frac{3}{4}} \\
& R^{\prime \prime}=-\frac{3 \lambda}{16}(t+C)^{-\frac{7}{4}}
\end{aligned}
$$

where,

$$
\lambda=\left(\frac{4 K a}{\rho_{s}}\right)^{\frac{1}{4}}
$$


It indicates that the temporal variation of the eroded path (expressed as Radius as function of time) follows the power function with a fixed power number of 0.25 . The constant $(C)$ depends on the boundary conditions (i.e., initial radius). The parameter of $\lambda$ reflects the information about soil properties and hydraulic conditions.

Hence, erosion coefficient can be obtained as

$$
K=\frac{\rho_{s} \lambda^{4}}{4 a}=\frac{\pi \rho_{s} \lambda^{4}}{16 \rho_{w} \nu \mathrm{X}}
$$

\subsection{Model for predicting soil loss in Hole Erosion Test (HET)}

In the HETs, the temporal variation of erosion can be understood explicitly under equation [21]. The accumulated soil loss is used for estimation of the radius expanded. The radius in the specimen is considered to be eroding uniformly, which is calculated by the following equations:

$$
\begin{gathered}
m=\rho_{s} \bullet V \\
m=\rho_{s} \bullet R \bullet 2 \pi R \bullet L \\
d m=2 \pi R L \rho_{s} \bullet d R \\
\int \mathrm{dm}=\int 2 \pi R L \rho_{s} \bullet d R \\
m=\pi L \rho_{s}\left(R^{2}-R_{0}^{2}\right) \\
R=\sqrt{\frac{m}{\pi \Lambda \rho_{s}}+R_{0}^{2}}
\end{gathered}
$$

As suggested in equation [21], erosion coefficient can be interpreted by the curve of the temporal variation of erosion with the parameter $(\lambda)$ in the HET. In order to simplify the calculation procedure to determine $\lambda$, equation [21] is transformed into,

$$
R^{4}=\lambda^{4}(t+C)
$$

Thus, a linear relationship is found between $R^{4}$ and $t$. The slope in the $R^{4}-t$ curve reflects $\lambda^{4}$. Based on the known $R(t)$, other physical quantities can be determined.

$$
\begin{aligned}
& \cdot=\rho_{s} \frac{\lambda}{4}(t+C)^{-\frac{3}{4}} \\
& \tau=\frac{4 \nu Q \rho_{w}}{\pi \lambda^{3}}(t+C)^{-\frac{3}{4}} \\
& \Delta P=\frac{8 \nu Q \rho_{w} L}{\pi \lambda^{4}(t+C)} \\
& m=\pi \Lambda \rho_{s}\left[\lambda^{2}(t+C)^{\frac{1}{2}} \quad-R_{0}^{2}\right]
\end{aligned}
$$


It should be noted that the applicability of these equations is under three assumptions as physical boundary conditions: 1) approximate homogeneity and continuity of soil material is adopted; 2) erosion is visualized as uniform at the fluid-soil interface; 3 ) the eroded radius has a physical limit due to the weakness of hydraulic shear stress in the erosion process (i.e., $R^{\prime}(t)=0$ ).

In the understanding of erosion process every concerned parameter, including erosion rate, hydraulic shear stress, and pressure drop, is linked with the determination of the radius. Based on equation [21], the radius is interpreted from the HET and other quantities could be further determined.

\section{Experimental methodology}

To validate the above proposed model, HETs were conducted. Experimental program including material properties, test setup, and procedures are described in the following sub-sections.

\subsection{Soil preparation}

The soil used for validation was sourced from the toe of mountains in the campus of Indian Institute of Technology Guwahati campus, India. Guwahati located in the northeastern part of India, experiences subtropical climate. The soil consisted of sand $(13 \%)$, silt $(65 \%)$, and clay $(22 \%)$. The liquid limit and plastic limit of the soil were measured as $32.0 \%$ and $24.8 \%$, respectively. According to the Unified Soil Classification System (USCS), the soil was identified as CL (sandy lean clay). As per the standard compaction tests (ASTM D 1140), the maximum dry density and optimum water content were found as $1.66 \mathrm{~g} / \mathrm{cm}^{3}$ and $18.8 \%$, respectively. Table 1 summarized the basic properties of the soil.

\subsection{Experimental setup and procedure}

Figure. 2 (a) shows the schematic diagram of in-house fabricated experimental setup for conducting HETs. As suggested by Wan and Fell (2004a) and Xie et al. (2018), the setup included a water tank, a soil specimen, and two chambers for inflow and outflow. The eroding fluid was supplied by the water tank with a high gravity potential. The fixed height of the water tank determined the constant head between two ends of the soil specimen. Flow rate in experiments can be adjusted by changing the height of the water tank. The soil specimen was compacted in an acrylic (transparent) cylindrical mold to form a small soil column with a diameter of $30 \mathrm{~mm}$ and a length of $50 \mathrm{~mm}$. A $7 \mathrm{~mm}$-diameter hole path was drilled at the center of the soil specimen along the axis (Ríha and Jandora 2015). The eroding fluid passed through the hole path to connect two chambers. The inflow chamber was filled with some gravels to stabilize the flow. The outflow chamber was connected to the atmosphere and the PVC collectors were used to receive the erosion.

The soil specimen was prepared at the maximum dry density with optimum moisture content. Before the tests, the prepared specimen was kept in a desiccator for 24 hours for moisture equalization. Initially, the inflow chamber and the hole path in the specimen were filled with the fluid slowly without causing any erosion. The head difference between the inlet and outlet of the specimen was adjusted for a flow rate and kept constant in each test. The erosion was continuously collected every 10 seconds to track the temporal variation of erosion. The test was performed until erosion became insignificant. This was judged based on visual inspection. The HETs were conducted under different hydraulic conditions (i.e. the variance of flow rates: $2920,4200,5450,7000,8400$, and $10000 \mathrm{ml} / \mathrm{min}$ ) to verify the stability of proposed model and also repeatability of tests.

\section{Interpretation of erosion process}

\subsection{Determination of erosion characteristics based on newly developed model}

As illustrated in Fig. 2(b), the soil specimens were eroded approximately axisymmetric during a HET. Although irregular eroded hole in the HETs was observed in the previous studies (Benaissa et al. 2012; Ríha and Jandora 2015; Lachouette et al. 2008; Xie et al. 2018), it was still reasonable to utilize a linear erosion 
law and homogeneity assumption to predict erosion enlargement (Benaissa et al. 2012). Hence, the results were presumptively reasonable to conduct further analyses.

Figure. 3 presented the observed erosion rate and extended radius in the erosion hole under six flow rates. The soil sample was subjected to erosion with a fixed flow rate. It is expected that erosion rate achieved is highest in the beginning. Erosion rate decreased gradually with time during the tests. The radius of the soil hole was continually increased until erosion rate became negligible. The results showed that eroded hole enlargement was nonlinear with time, which is in agreement with the previous studies of Sterpi (2003), Cividini and Gioda (2004), Wilson (2009), and Jiang and Soga (2019). The developed equation [21] was applied for explanation of the temporal variation of erosion in the tests. The data of radius was successfully fitted by equation [21]. In general, the fitted equation indicated that $R(t)$ did follow the function of time, with an exponent of 0.25 . As explained in equation [14], erosion rate could be reviewed to obey the first derivative equation of $R(t)$. Thus, equation [33] was used to fit the data of erosion rate over time. Although both equations are describing the same erosion process, it should be noted that the goodness-of-fit of equation [21] is higher than equation [33].

As indicated in Fig. 4, proposed equations (equation [21] and [36]) fitted considerably with the temporal variation of erosion. Eroded depth was found to reduce with time. It can be also visualized that rate of change of hole size (as indicated in Fig. 2(b)) gradually becomes negligible at the end of test. It was found from Fig. 4 that eroded depth and cumulative soil loss increased with flow rate. Based on the corresponding deformation of the soil pipe, the mechanical characteristics (i.e. hydraulic shear stress and water pressure) were obtained and interpreted in the soil pipe, as documented in Fig. 5. The variation of hydraulic shear stress and pressure drop showed a similar trend with erosion rate over time. The decline of hydraulic shear stress led to the decrease of erosion rate and eroded depth as also observed from erosion law (Wall and Fell 2004). As observed from equation [12], hydraulic shear stress decreased with an enlargement of hole over time. A higher flow rate resulted into higher hydraulic shear stress and pressure drop. Interestingly, at the latter half of tests, hydraulic shear stresses of different flow rates became constant, which is defined as equilibrium shear stress in the current study. The equilibrium shear stress $\left(\tau_{e}\right)$ will be further discussed in the next section. The recorded profile of pressure drop is consistent with that of Benahmed and Bonelli (2012). The pressure drop was balanced in the final phase of the experiment, which was referred as the semiequilibrium condition in the study of Wilson (2009). This result supports the opinion that the generated pore water pressure from a high hydraulic gradient would be dissipated attributed to the enlargement of the soil pipe (Hicher 2013; Ouyang and Takahashi 2016). Hydraulic non-equilibrium within soil pipes would be exhausted by soil erosion and the hydraulic potential energy would be diminished during the process of sediment detachment and transport (Wilson et al. 2009; Sang et al. 2015; Nguyen and Indraratna 2020).

To interpret erosion characteristics, the $R^{4}-t$ curves were plotted based on equation [32]. As indicated in Fig. 6 (a), proportional relationship between $R^{4}$ and time was found in each experiment for different flow rates. Table 2 summarized the interpretation of erosion characteristics. Equation [32] was used to fit the data of HET. The slopes of the best-fit lines reflected the values of $\lambda$. Equation [25] was used to determine erosion coefficient based on the results from equation [32]. Fig. 6 (b) proves that $\lambda^{4}$ is proportional to flow rate for a given soil as indicated in Equation [25]. This theoretically suggests that the erosion coefficient is likely to remain constant under different experimental conditions (Indraratna et al. 2008).

\subsection{Difference in erosion characteristics as determined from traditional and new model}

The interpretation of erosion characteristics from traditional model (Equation 1) was based on the relationship of erosion rate with hydraulic stress, as depicted in Fig. 7 (a). Erosion coefficient and critical shear stress can be inferred from the slope and horizontal intercept of curve, respectively. In the current study, the $\dot{\varepsilon}-\tau$ curves were also presented, as shown in Fig. 7 (b). However, the temporal variation of the two curves is reversed so that the physical definition of the horizontal intercept is changed. Critical shear stress is the hydraulic shear stress when the erosion happens initially (Wall and Fell 2004b). However, the horizontal intercept in the current study is the hydraulic shear stress at the end of experiment. Therefore, this quantity is newly defined as equilibrium shear stress. Critical shear stress was proposed to formulate the criteria of 
hydraulic earth construction to prevent erosion (Arulanandan and Perry 1983). Similarly, equilibrium shear stress would be suggested to the consideration of post-construction risk assessment. As indicated in Table 3, the determination of equilibrium shear stress also showed the stability of the measurement approach with a nearly constant value of $0.08 \mathrm{~Pa}$.

Even though erosion characteristics could be obtained from the $\dot{\varepsilon}-\tau$ curves, some errors of the interpretation from the curves happened due to the theoretical discretization of model application. As described in Fig. 6 , erosion coefficient could be deduced from the continuous $R^{4}-t$ curves. This approach is recommended by the current study. Only after $R(t)$ is known from experiments, other quantifies can be calculated. The model of $R(t)$ has no issue of discretization since the instantaneous data of $R(t)$ is collected and analyzed. In contrast, the measurement of erosion rate considering the average soil loss at a time interval results into the deviation induced by discretization. Besides, equation [22] and Fig. 4 suggest that variation of erosion rate with time should follow the concave function. Therefore, it implies that the instantaneous erosion rate should be theoretically and slightly higher than the measured erosion rate.

The comparison between the traditional and new model for obtaining erosion characteristics was analyzed, as shown in Fig. 8. Traditionally, erosion characteristics can be developed from the $\dot{\varepsilon}-\tau$ curves based on equation [1]. The $\dot{\varepsilon}-\tau$ curves plotted with measured data should be fitted by linear relationships. However, some subtle fluctuations appeared in curves due to the problem of discretization. With the interpretation from $R^{4}-t$ curves, the theoretical $\dot{\varepsilon}-\tau$ curves were predicted. Measured $\dot{\varepsilon}-\tau$ curves generally coincided with the prediction model. Table 4 summarized the outcomes of the two models. The values of erosion coefficient provided from $R^{4}-t$ model were slightly higher than those developed from the $\dot{\varepsilon}-\tau$ curves. However, the performance of fitting of $R^{4}-t$ model is better than the traditional model, as shown in the comparison of the determination coefficient $\left(\mathrm{R}^{2}\right)$. Besides, the results from traditional model showed higher variance among the HETs.

Comparison between predicted and measured erosion behavior (from Fig. 8) can be generalized as shown in Fig. 9. Erosion process during HET can be categorized into three phases, namely initial phase, normal phase, and final phase. At the initial phase, the measurement is lower than the idealization of the model because it needs some time to initiate erosion with the existence of critical shear stress. The second phase is expected as the erosion variation is almost close to the theoretical model. At the final phase, the erosion coefficient is strengthened, which results into the rapid failure of the soil body and achieves the equilibrium of hydraulic shear stress and erosion resistance of the soil. Fell et al. (2003) also categorized the erosion process of infrastructure failure into four phases, includinginitiation, continuation, progression, andformation . These two distinction methods are similar and complementary to each other. The initial phase and final phase share the same definition with the first and fourth phases in the study of Fell et al. (2003), respectively. The normal phase is parallel to the combined phases of continuation and progression. The concept of three phases is suitable for small-scale experiments, while the four-phase analysis is used in large-scale tests. Both two models are necessary to understand the erosion process from laboratory tests to field surveillance. Results from both current experiments and previous studies suggested that the erosion coefficient would slightly increase with elapsing time. This weakness of erosion resistance is attributed by the reduction of Young's modulus and possible enhancement of permeability during the HETs (Parron Vera et al. 2014; Jiang and Soga 2019). Progressive internal erosion reduces the sliding resistance at interparticle contact, triggering macroscopic deformations and even failure of the soil specimen (Hicher 2013). This explains the nonlinear relationships between applied shear stress and the erosion rate in the study of (Khanal et al. 2016). Therefore, it is significant to understand the stage of the erosion variation to react the erosive responses.

\subsection{Discussion on application of newly proposed model in predicting erosion from tests conducted in literature}

To further verify the applicability of the proposed model, the available data from literature work is collected and performed the redetermination of erosion characteristics, as shown in Fig. 10 and Fig. 11. The studies of Indraratna et al. (2008) and Xie et al. (2018) recorded the temporal variation of the concerned parameters in the HET. The current model shows considerable consistency and adaptation in predicting erosion variation. The instantaneous recording included erosion rate, hydraulic shear stress, water pressure, eroded depth, 
and radius. Indraratna et al. (2008) plotted logarithmic coordinates to find the linear relationship between erosion rate/hydraulic shear stress and logarithm of time. Since the equations of concerned parameters are found as power functions in this study, it is reasonable to obtain the linearity in the logarithmetic scale. Although the experimental results of Xie et al. (2018) indicated that the hole enlargement was not perfectly symmetrical and uniform during continuous erosion due to the friction loss at the entrance of the hole (Ř́lha and Jandora 2015), the erosion process appears to be generally predicted by the new model. It might be attributed that the energy loss at the entrance of the hole is minor as compared to the energy dissipation of sediment detachment and transport. Nguyen and Indraratna (2020) also suggested that a large percentage of the input energy in the fluid flow was dissipated by soil erosion. Further, the energy was transferred to the kinetic component of soil particles was negligible. Ouyang and Takahashi (2016), Fattahi et al. (2017), Jiang and Soga (2019), and Zhang et al. (2020) also performed HETs and explored internal erosion process on various soils. Cumulative eroded soil loss (from equation [36]), shows considerable performance of fitting. However, it should be noted that prediction ability cannot be judged completely since, the soil properties and experimental setups in the above studies were different. The erosion trend of these studies can be generally captured. However, the cumulative eroded soil loss at the final phase is slightly overestimated by proposed equations, as shown in Fig. 10 (d) and Fig. 11 (a-d). This might be resulted from the effects of sediment clogging in long-scale soil pipes (Wilson and Fox 2013). Soil particles were accumulated and entrapped in the latter part of soil pipes, when the residual fluid energy after dissipating in the sediment detachment could not support the entire process of sediment transport. Therefore, the estimated soil loss is marginally larger than the measured sediment and the water pressure is subtly higher than the prediction.

Seepage tests have been used to investigate the influence of internal erosion (Tomlinson and Vaid 2000). New model might be useful to estimate the settlement and strain of the soil body subjected to internal erosion by following the mass conservation law. The dynamic measurement of soil settlement and strain in the previous studies (Tomlinson and Vaid 2000; Marot et al. 2010; Ouyang and Takahashi 2016; Sato and Kuwano 2018; Indiketiya et al. 2019) was approximately observed to obey the equation [36]. This is because the deformation of soil body is attributed to the soil loss. If the subtle change of soil strength properties is ignored, the prediction of the soil loss would roughly explain the settlement and strain of the soil (Indraratna et al. 2009). Hence, the theoretical model might be significant to explain the mechanism and influence of erosion process in the HET, soil erosion, soil deformation, and even the instability of earth structures.

\section{Conclusion}

In this study, a new simple theoretical model was developed based on Bernoulli's principle to understand the erosion process in the hole erosion test (HET). The constitutive equation of erosion characteristics was further developed into a differential equation to find out the dynamic prediction model of erosion process. It was found that eroded hole radius as a function of time $(R(t))$ followed the power function with an exponent of 0.25 . Based on the known $R(t)$, other physical quantities namely erosion rate, pressure drop, and erosion characteristics can be deduced. Besides, a new equation was proposed to determine the erosion coefficient by observing the realistic change of hole radius (soil loss). The model was validated with HETs for various flow conditions. Model performance was also evaluated based on tests conducted in the literature. These was reasonably good agreement between measured and predicted erosion characteristics (from newly developed model) under different hydraulic conditions. Furthermore, the reported phenomenon of HETs in the literature was considerably interpreted by proposed equations. The interpreted experimental results suggested that erosion coefficient marginally increased during the entire process of internal erosion in HET. Three distinct phases (i.e. initial, normal, and final phases) were used to explain the internal erosion process in HET. The advantage of the proposed model is that the erosion characteristics are determined by considering the realistic measured change in radius of the soil hole. The proposed formulation in this study was tested only for HETs. However, further studies are needed to understand its applicability for determining the internal erosion in various geotechnical infrastructures in the field.

\section{Acknowledgement}

Authors would like to thank national natural science foundation (NSFC) of China for grant (No. 41907252). 


\section{Data availability statement}

The data that support the findings of this study are available on request from the corresponding author. The data are not publicly available due to privacy or ethical restrictions.

\section{References}

Arulanandan, K., \& Perry, E. B. (1983). Erosion in relation to filter design criteria in earth dams. Journal of Geotechnical Engineering, 109(5), 682-698. https://doi.org/10.1061/(ASCE)0733-9410(1983)109:5(682)

ASTM. Committee D18 on Soil and Rock. (2006). Standard test method for identification and classification of dispersive clay soils by the pinhole test. ASTM International. https://doi.org/10.1520/D4647_D4647M-13

Benahmed, N., \& Bonelli, S. (2012). Investigating concentrated leak erosion behaviour of cohesive soils by performing hole erosion tests. European Journal of Environmental and Civil Engineering, 16(1), 43-58. https://doi.org/10.1080/19648189.2012.667667

Benaissa, K., Angel, P. V. M., Dlolores, R. C. M., Philippe, D., Abdellatif, K., Mohammed, B., \& Larbi, E. B. (2012). Predicting initial erosion during the hole erosion test by using turbulent flow CFD simulation. Applied Mathematical Modelling, 36(8), 3359-3370. https://doi.org/10.1016/j.apm.2011.04.036

Bernatek-Jakiel, A., \& Poesen, J. (2018). Subsurface erosion by soil piping: significance and research needs. Earth-Science Reviews, 185, 1107-1128. https://doi.org/10.1016/j.earscirev.2018.08.006

Bonelli, S., \& Brivois, O. (2008). The scaling law in the hole erosion test with a constant pressure drop. International Journal for Numerical and Analytical Methods in Geomechanics, 32(13), 1573-1595. https://doi.org/10.1002/nag.683

Bonelli, S., Brivois, O., Borghi, R., \& Benahmed, N. (2006). On the modelling of piping erosion. Comptes Rendus Mécanique, 334(8-9), 555-559. https://doi.org/10.1016/j.crme.2006.07.003

Briaud, J. L., Ting, F. C. K., Chen, H. C., Cao, Y., Han, S. W., \& Kwak, K. W. (2001). Erosion function apparatus for scour rate predictions. Journal of geotechnical and geoenvironmental engineering, 127(2), 105113. https://doi.org/10.1061/(ASCE)1090-0241(2001)127:2(105)

Chang, D., Zhang, L. M., Xu, Y., \& Huang, R. (2011). Field testing of erodibility of two landslide dams triggered by the 12 May Wenchuan earthquake. Landslides, 8(3), 321-332. https://10.1007/s10346-011-0256-x

Chang, D. S., \& Zhang, L. M. (2013). Extended internal stability criteria for soils under seepage. Soils and Foundations, 53(4), 569-583. https://doi.org/10.1016/j.sandf.2013.06.008

Cividini, A., \& Gioda, G. (2004). Finite-element approach to the erosion and transport of fine particles in granular soils. International Journal of Geomechanics, 4(3), 191-198. https://doi.org/10.1061/(ASCE)15323641(2004)4:3(191)

Cividini, A., Bonomi, S., Vignati, G. C., \& Gioda, G. (2009). Seepage-induced erosion in granular soil and consequent settlements. International Journal of Geomechanics, 9(4), 187-194. https://doi.org/10.1061/(ASCE)1532-3641(2009)9:4(187)

Dumberry, K., Duhaime, F., \& Ethier, Y.A. (2017). Erosion monitoring during core overtopping using a laboratory model with digital image correlation and x-ray microcomputed tomography. Canadian Geotechnical Journal, cgj-2016-0684. https://doi.org/10.1139/cgj-2016-0684

Elkholy, M., Sharif, Y. A., Chaudhry, M. H., \& Imran, J. (2015). Effect of soil composition on piping erosion of earthen levees. Journal of Hydraulic Research, 53(4), 478-487. http://dx.doi.org/10.1080/00221686.2015.1026951

Fattahi, S. M., Soroush, A., \& Shourijeh, P. T. (2017). The Hole Erosion Test: A Comparison of Interpretation Methods. Geotechnical Testing Journal, 40(3), 494-505. https://doi.org/10.1520/GTJ20160069 
Fell, R., Wan, C. F., Cyganiewicz, J., \& Foster, M. (2003). Time for development of internal erosion and piping in embankment dams. Journal of geotechnical and geoenvironmental engineering, 129(4), 307-314. https://doi.org/10.1061/(ASCE)1090-0241(2003)129:4(307)

Foster, M., Fell, R., \& Spannagle, M. (2000). The statistics of embankment dam failures and accidents. Canadian Geotechnical Journal, 37(5), 1000-1024. https://doi.org/10.1139/t00-030

Foster, M., Fell, R., \& Spannagle, M. (2002). A method for assessing the relative likelihood of failure of embankment dams by piping: reply. Canadian Geotechnical Journal, 39(2), 497500. https://doi.org/10.1139/t01-109

Haghighi, I., Chevalier, C., Duc, M., Guédon, S., \& Reiffsteck, P. (2013). Improvement of Hole Erosion Test and Results on Reference Soils. Journal of Geotechnical and Geoenvironmental Engineering, 139(2), 330-339. https://doi.org/10.1061/(ASCE)GT.1943-5606.0000747

Hicher, P.-Y. (2013). Modelling the impact of particle removal on granular material behaviour. Géotechnique, 63(2), 118-128. http://dx.doi.org/10.1680/geot.11.P.020

Indiketiya, S., Jegatheesan, P., Rajeev, P., \& Kuwano, R. (2019). The influence of pipe embedment material on sinkhole formation due to erosion around defective sewers. Transportation Geotechnics, 19, 110-125. https://doi.org/10.1016/j.trgeo.2019.03.001

Indraratna, B., Muttuvel, T., Khabbaz, H., \& Armstrong, R. (2008). Predicting the erosion rate of chemically treated soil using a process simulation apparatus for internal crack erosion. Journal of Geotechnical and Geoenvironmental Engineering, 134(6), 837-844. https://doi.org/10.1061/(ASCE)1090-0241(2008)134:6(837)

Indraratna, B., Muttuvel, T., \& Khabbaz, H. (2009). Modelling the erosion rate of chemically stabilized soil incorporating tensile force - deformation characteristics. Canadian Geotechnical Journal, 46(1), 5768. https://doi.org/10.1139/t08-103

Jiang, N.-J., \& Soga, K. (2019). Erosional behavior of gravel-sand mixtures stabilized by microbially induced calcite precipitation (MICP). Soils and Foundations, 59, 699-709. https://doi.org/10.1016/j.sandf.2019.02.003

Khanal, A., Klavon, K. R., Fox, G. A., \& Daly, E. R. (2016). Comparison of linear and nonlinear models for cohesive sediment detachment: rill erosion, hole erosion test, and streambank erosion studies. Journal of Hydraulic Engineering, 142(9), 04016026.1-04016026.12. https://doi.org/10.1061/(ASCE)HY.19437900.0001147

Lachouette, D., Golay, F., \& Bonelli, S. (2008). One-dimensional modeling of piping flow erosion. Comptes Rendus Mécanique, 336(9), 731-736. https://doi.org/10.1016/j.crme.2008.06.007

Marot, D., Sail, Y., \& Alexis, A. (2010). Experimental Bench for Study of Internal Erosion in Cohesionless Soils. International Conference on Scour \& Erosion. https://doi.org/10.1061/41147(392)40

Nadal-Romero, E., Verachtert, E., Maes, R., \& Poesen, J. (2011). Quantitative assessment of the piping erosion susceptibility of loess-derived soil horizons using the pinhole test. Geomorphology, 135(1-2), 66-79. https://doi.org/10.1016/j.geomorph.2011.07.026

Nguyen, T. T., \& Indraratna, B. (2020). The energy transformation of internal erosion based on fluid-particle coupling. Computers and Geotechnics, 121, 103475. https://doi.org/10.1016/j.compgeo.2020.103475

Nieber, J. L., Wilson, G. V., \& Fox, G. A. (2019). Modeling Internal Erosion Processes in Soil Pipes: Capturing Geometry Dynamics. Vadose Zone Journal, 18(1). https://10.2136/vzj2018.09.0175

Onate, E., Celigueta, M. A., Idelsohn, S., Salazar, F., \& Suarez, B. (2011). Possibilities of the particle finite element method for fluid - soil-structure interaction problems. Computational Mechanics, 48(3), 307-318. https://10.1007/s00466-011-0617-2 
Ouyang, M., \& Takahashi, A. (2016). Influence of initial fines content on fabric of soils subjected to internal erosion. Canadian Geotechnical Journal, 53(2), 299-313. https://doi.org/10.1139/cgj-2014-0344

Parron Vera, M. A., Yakhlef, F., Rubio Cintas, M. D., Castillo Lopez, O., Dubujet, P., Khamlichi, A., \& Bezzazi, M. (2014). Analytical solution of coupled soil erosion and consolidation equations by asymptotic expansion approach. Applied Mathematical Modelling, 38(15-16), 4086-4098. http://dx.doi.org/10.1016/j.apm.2014.02.006

Pereyra, M. A., Fernández, D. S., Marcial, E. R., \& Puchulu, M. E. (2019). Agricultural land degradation by piping erosion in Chaco Plain, Northwestern Argentina. CATENA, 104295. https://doi.org/10.1016/j.catena.2019.104295

Ř́íha, J., \& Jandora, J. (2015). Pressure conditions in the hole erosion test. Canadian Geotechnical Journal, 52(1), 114-119. https://doi.org/10.1139/cgj-2013-0474

Sang, J., Allen, P., Dunbar, J., \& Hanson, G. (2015). Development of semi-physically based model to predict erosion rate of kaolinite clay under different moisture content. Canadian Geotechnical Journal, 52(5), 577586. https://doi.org/10.1139/cgj-2012-0274

Sato, M., \& Kuwano, R. (2018). Laboratory testing for evaluation of the influence of a small degree of internal erosion on deformation and stiffness. Soils and Foundations, 58(3), 547-562. https://doi.org/10.1016/j.sandf.2018.01.004

Sterpi, D. (2003). Effects of the Erosion and Transport of Fine Particles due to Seepage Flow. International Journal of Geomechanics, 3(1), 111-122. https://doi.org/10.1061/(asce)1532-3641(2003)3:1(111)

Tomlinson, S. S., \& Vaid, Y. P. (2000). Seepage forces and confining pressure effects on piping erosion. Canadian Geotechnical Journal, 37(1), 1-13. https://doi.org/10.1139/t99-116

Wan, C. F., \& Fell, R. (2004a). Investigation of rate of erosion of soils in embankment dams. Journal of geotechnical and geoenvironmental engineering, 130(4), 373-380. https://doi.org/10.1061/(ASCE)10900241(2004)130:4(373)

Wan, C. F., \& Fell, R. (2004b). Laboratory tests on the rate of piping erosion of soils in embankment dams. Geotechnical testing journal, 27(3), 295-303. https://doi.org/10.1520/GTJ11903

Wilson, G. V. (2009). Mechanisms of ephemeral gully erosion caused by constant flow through a continuous soil-pipe. Earth Surface Processes and Landforms, 34(14), 1858-1866. https://doi.org/10.1002/esp.1869

Wilson, G. V., \& Fox, G. A. (2013). Pore-water pressures associated with clogging of soil pipes: Numerical analysis of laboratory experiments. Soil Science Society of America Journal, 77(4), 1168-1181. https://doi.org/10.2136/sssaj2012.0416

Wilson, G. V., Nieber, J. L., Sidle, R. C., \& Fox, G. A. (2013). Internal Erosion during Soil Pipeflow: State of the Science for Experimental and Numerical Analysis. Transactions of the ASABE, 56(2), 465-478. https://10.13031/2013.42667

Wilson, G. V., Wells, R. R., Kuhnle, R. A., Fox, G. A., \& Nieber, J. L. (2018). Sediment detachment and transport processes associated with internal erosion of soil pipes. Earth Surface Processes and Landforms, 43(1), 45-63. https://doi.org/10.1002/esp.4147

Xie, L., Liang, X., \& Su, T.-C. (2018). Measurement of pressure in viewable hole erosion test. Canadian Geotechnical Journal, 1-8. http://dx.doi.org/10.1139/cgj-2017-0292

Yang, J., Yin, Z.-Y., Laouafa, F., \& Hicher, P.-Y. (2020). Hydromechanical modeling of granular soils considering internal erosion. Canadian Geotechnical Journal, 57(2), 157-172. https://doi.org/10.1139/cgj-2018-0653

Zhang, D.-M., Du, W.-W., Peng, M.-Z., Feng, S.-J., \& Li, Z.-L. (2020). Experimental and numerical study of internal erosion around submerged defective pipe. Tunnelling and Underground Space Technology, 97, 
103256. https://doi.org/10.1016/j.tust.2019.103256

\section{Hosted file}

Figures-2020.07.21.docx available at https://authorea.com/users/346084/articles/472187-anovel-analytical-model-for-determining-erosion-from-hole-erosion-tests

\section{Hosted file}

Tables-2020.07.21.docx available at https://authorea.com/users/346084/articles/472187-anovel-analytical-model-for-determining-erosion-from-hole-erosion-tests 